\title{
Infant's giant obstructive ureterocele causing bladder neck obstruction
}

\begin{abstract}
A ureterocele is a congenital abnormality found in the ureter, whereas the distal ureter balloons at its opening into the bladder, form a sac-like pouch; often associated with a duplicated collection system, whereas ureters drain their respective kidneys instead of one. Simple ureterocele: The case that involves single ureter represents only twenty percent of total cases. Ureterocele affects one out of 4000 individuals; at least fourfifths of female patients. This forms a rare case of an eleven-month old girl with multiple urine tract abnormalities, super giant obstructive ureterocele touching the dome of urinary bladder at cystoscopy view, associated to bilateral duplex system causing hypoplastic upper moiety of right kidney and secondary vesico-ureteral reflux (VUR) in the left side.
\end{abstract}

Volume 6 Issue 3 - 2018

\author{
Yasin Idweini \\ Senior Consultant of Urology, Al Bashir Teaching Hospital \\ Amman, Jordan
}

Correspondence: Yasin Idweini, Senior Consultant of Urology, Al Bashir Teaching Hospital Amman, Jordan, Tel 0096279733 I987, Email yasin_idweini@hotmail.com

Received: May 24, 2018 | Published: June 06, 2018

Keywords: obstructive, ureterocoele, giant, bilateral, duplication, secondary VUR marsupialization, hemi nephroureterectomy

Abbreviations: VUR, vesico-ureteral reflux; UTI, urine tract infection; MCUG, micturating cystourethrogram

\section{Introduction}

Ureterocele is a sacculation of the terminal portion of the ureter, it may be either intravesical or ectopic. In the latter case, some portion is located at the bladder neck or in the urethra. Intravesical ureteroceles are, often, associated with single ureter whereas ectopic ureterocele mostly involves the upper pole of duplicated ureters. Ectopic ureterocele are four times more common than ureterocoele of normal located orifice. ${ }^{1}$ Ureterocele has been attributed to delayed or incomplete canalization of the ureteral bud; that lead to an early prenatal obstruction and expansion of the ureteral bud, before being absorbed into the urogenital sinus. ${ }^{2}$ The cystic dilatation was formed between the superficial and deep muscles layers of the trigone. They, most frequently, occur in females (4:1 ratio). Approximately $10 \%$ are bilateral.

\section{Case presentation}

Sajida is an 11-month female patient was referred from the paediatric department, cachectic, with recurrent episode of urine tract infection (UTI) and dysuria. Upon physical examination; cachectic, malnourished, abdominal distension with both kidneys were noticed.

The laboratory results are: $\mathrm{Hb} 12 \mathrm{gr} / \mathrm{dl}, \mathrm{WBC} 19400, \mathrm{~S}$. Createnine 33umol/1, B.Urea 4.6mmol/1,Na140meq/1,K4.4 meq/1

Urine analysis presents WBC numerous, RBC 2-4, considerable number of bacteria. The (IVU) urogram displayed giant obstructive right ureterocele bilateral duplication, non-functioning obstructed upper moiety of right kidney, lower moiety ureterohydronehrosis of left kidney (Figure 1) (Figure 2).

The patient micturating cystourethrogram (MCUG) showed large filling defect arising from the posterior wall of the urinary bladder with secondary left VUR.

The cystoscopy showed super giant right ureterocele; obstructing the bladder neck making the procedure difficult, due to the limited infant bladder's space that is filled by the giant ureterocele and further aborted and the procedure shifted to opened cystostomy and marsupialization. of the ureterocele was performed.

It was noticed that she has gained weight and her condition is generally improved after her discharge and follow-up procedures.

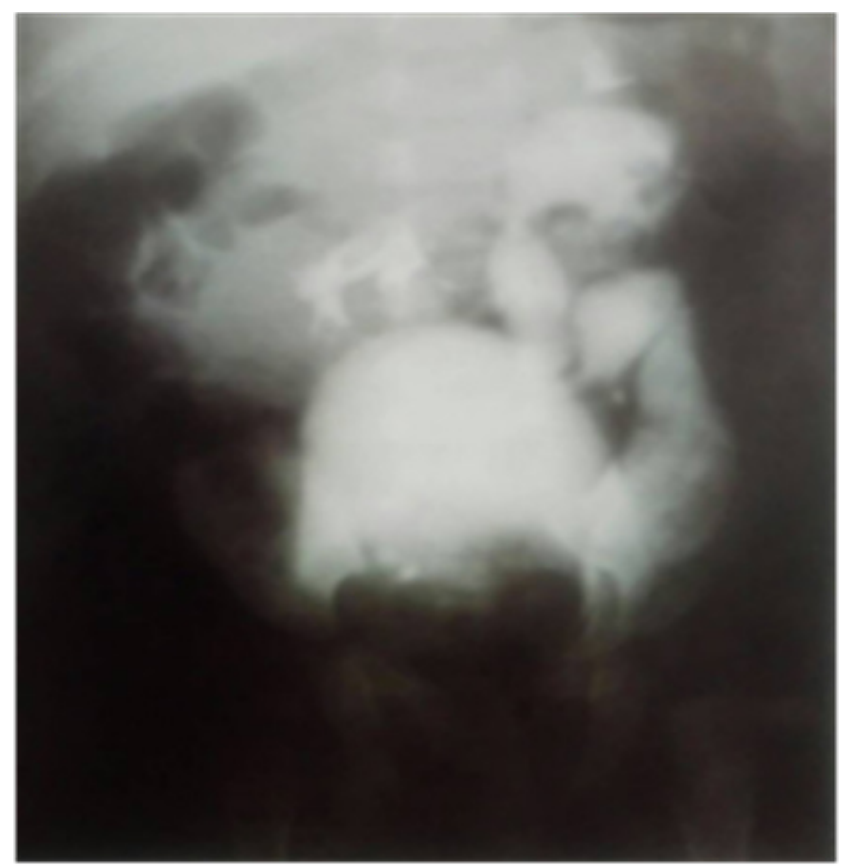

Figure I IVU obstructive ureterocele, non-functioning upper moiety of right kidney, severe ureterohydronephrosis of left kidney.

After one year of follow-ups, the opened cystostomy and marsupialization of the ureterocele, MCUG was performed and showed irregular wall of the urinary bladder, right sided (VUR), with severe tortuosity dilatation of the ureter and severe hydronephrotic changes in the collecting system of right kidney, with Lt secondary VUR (Figure 3). 
Then we decided to do right heminephroureterectomy of the nonfunction upper moiety. The witnessed postoperative course registered uneventful.

Three months later postoperative (IVU) was performed and showed normal functioning of both kidneys (Figure 4). Six months

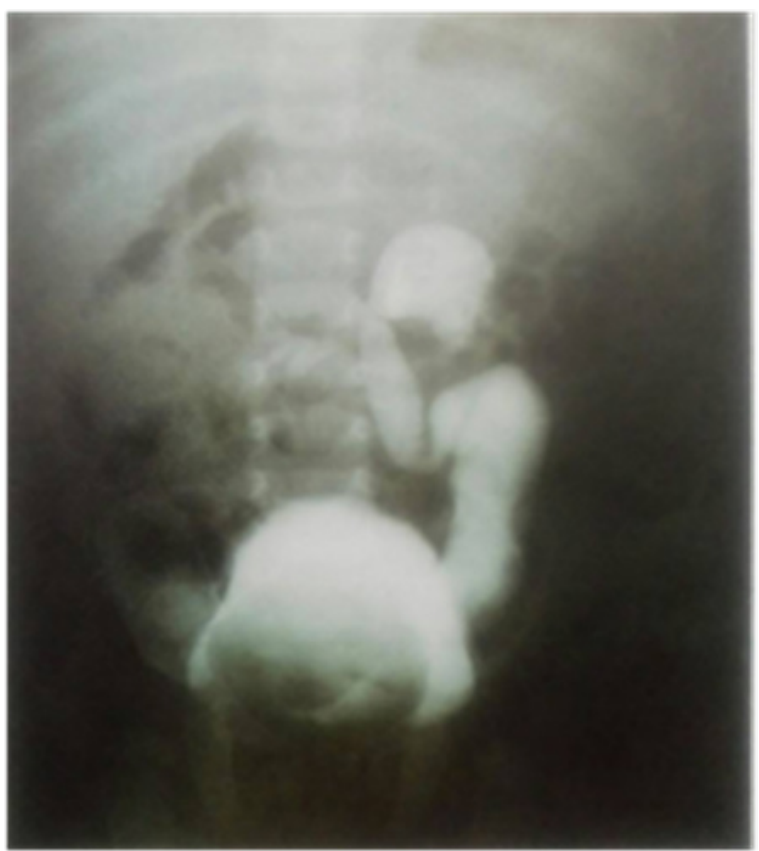

Figure 2 IVU delayed film after 5 hours: showed still retained contrast in dilated left ureter and pelvis and bladder due to the obstructive ureterocele.

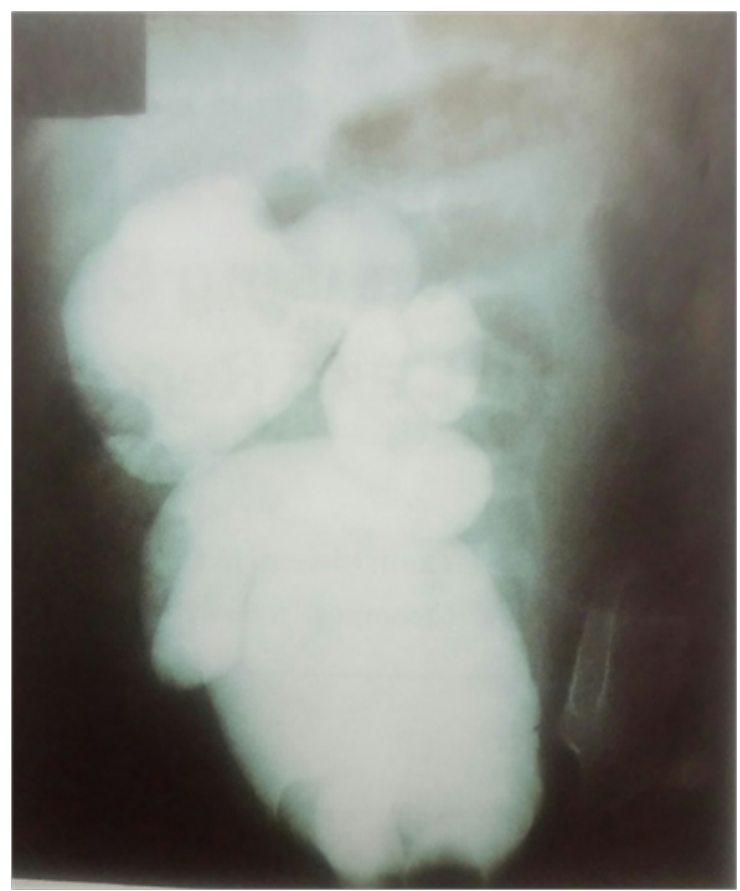

Figure 3 MCUG after marsupialization of the obstructed ureterocoele: showed severe right VUR 5 degree and secondary left VUR. later; postoperative (MCUG) showed normal cystourethrogram except an active left sided VUR (First degree) which did not need further treatment (Figure 5A) (Figure 5B). ${ }^{1}$ In the last follow-up of the girl Sajida about 4 years ago when her age was 15 -year old, she was asymptomatic, active and healthy beautiful girl without any urological symptoms and we stopped follow-up because of normal exploration.

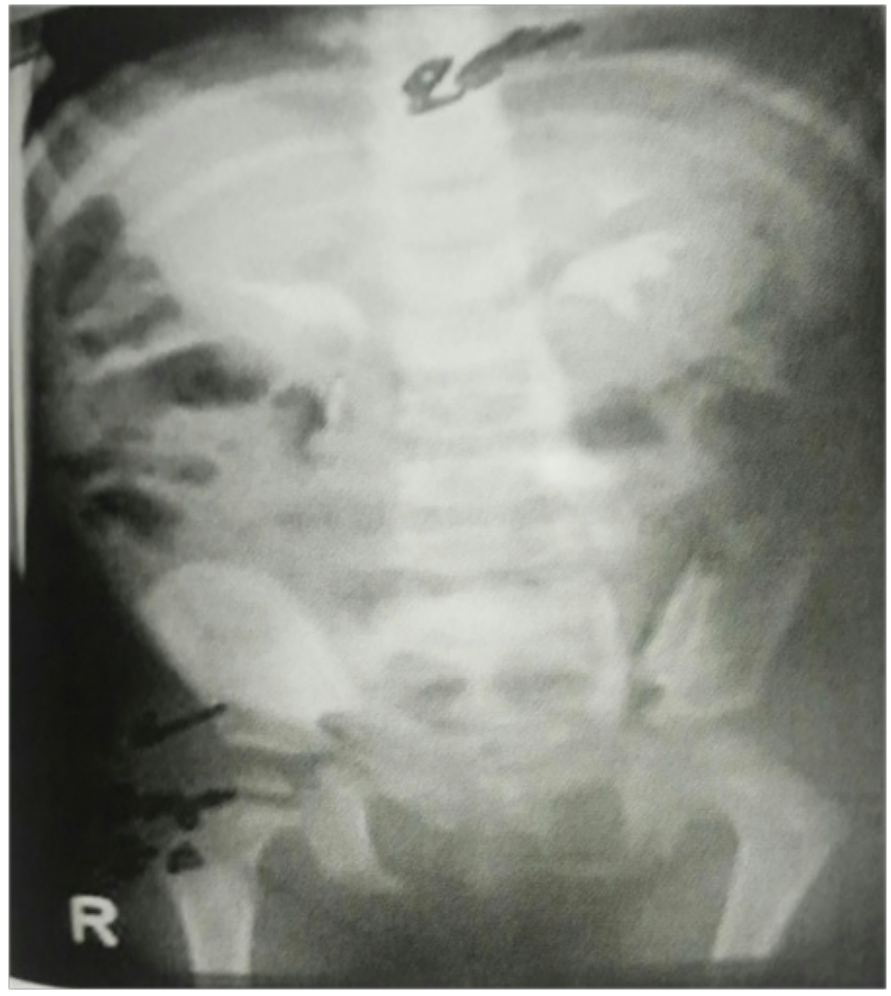

Figure 4 Postoperative IVU: showed normal functioning both kidneys after right hemi nephroureterectomy of the upper non function moiety.

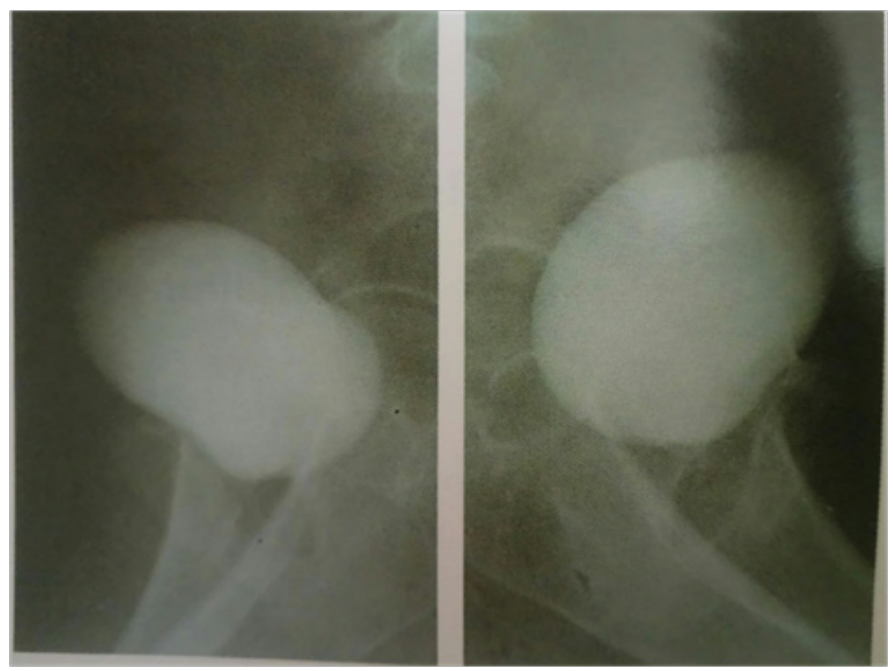

Figure 5(A) MCUG, during filling after one year of right heminephroureterectomy of the upper moiety:VUR were corrected. 


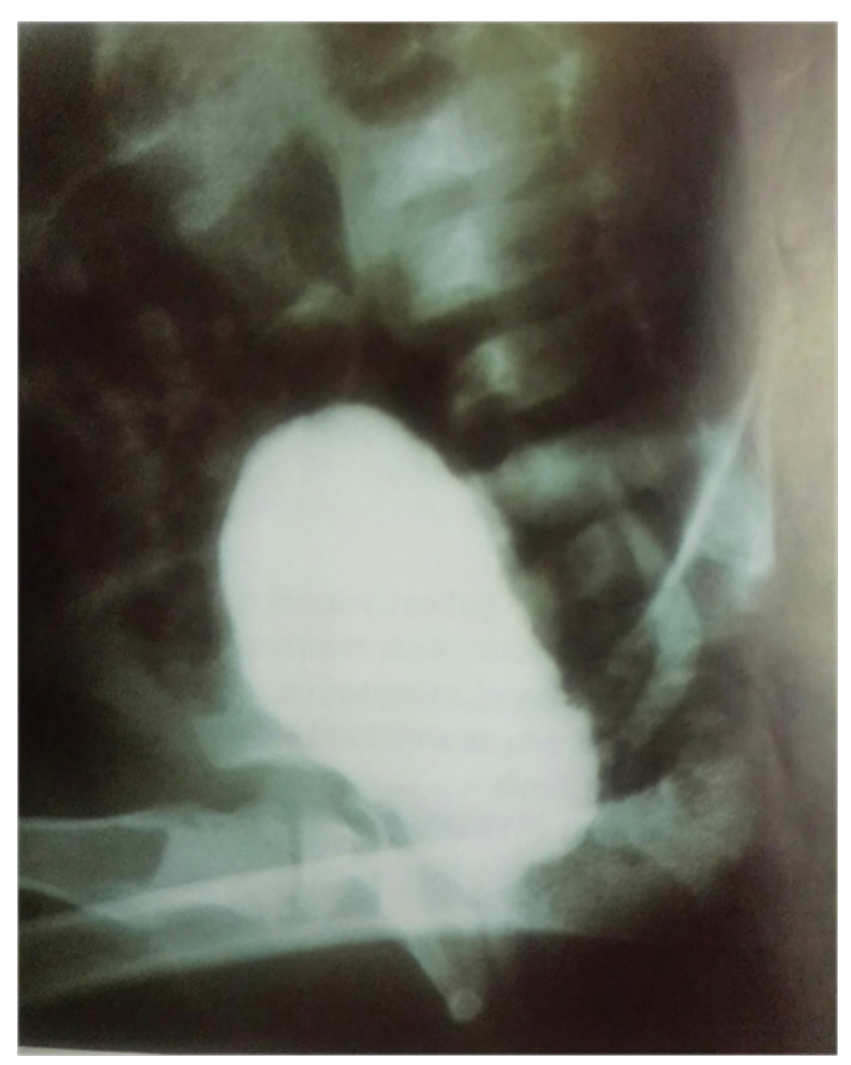

Figure 5(B) MCUG, during micturition after Hemi-nephroureterectomy: showed normal cystogram except only mild first-degree left active VUR.

\section{Discussion and conclusion}

Large ureteroceles may displace the other orifice, interfere with the muscular backing of the bladder, or even obstruct the bladder outlet. We almost noticed a significant hydroureteronephrosis, and a dysplastic segment of the upper pole of the kidney which was found in association with a ureterocele. Clinical findings in such cases vary considerably. Patients, commonly, present with infection, but bladder outlet obstruction, as in the discussed case, or incontinence may be the initial complaint. Occasionally, the ureterocele may prolapse through the female urethra. ${ }^{3}$ Calculi can develop secondary to urinary stasis.

Many cases are diagnosed by antenatal maternal ultrasound (U/S). ${ }^{4}$ Excretory urography(IVU) is usually diagnostic and may show a cystic dilatation on a filling defect in the bladder (cobra head deformity).

IVU also indicates the degree of hydro nephrosis and may reveal a duplicated collecting system of the kidney. Voiding cystourethrography should always be part of the work up. ${ }^{5}$ Treatment must be individualized. Transurethral incision was used previously only in very ill children with pyohydronephrosis; however, it has been recognized; as the definitive procedure in many instances particularly in patients with intravesical ureterocoele. ${ }^{6,7}$ When an open operation is needed, the procedure must be chosen on the basis of the anatomic location of the ureteral meatus, the position of the ureterocele, the degree of hydroureteronephrosis and impairment of renal function. In general, choices range from heminephrectomy and ureterectomy by performing opened or laparoscopic operation, ${ }^{7,8}$ to excision of the ureterocele, or vesical reconstruction and ureteral reimplantation., ${ }^{9,10}$

\section{Acknowledgements}

None.

\section{Conflict of interest}

The author declares there is no conflict of interest.

\section{References}

1. Synder HM, Johnston JH. Orthotopic ureterocoeles in children. J Urol. 1978;119(4):543-6.

2. Tanagho EA. Embryologic basis for lower ureteral anomalies: a hypothesis. Urology. 1976;7(5):451-64.

3. Ahmed S. Prolapsed single system ureterocoele in a girl. $J$ Urol. 1984;132(6):1180.

4. Gloor JM, Ogburn P, Matassumoto J. Prenatally diagnosed. Ureterocele presenting as foetal bladder outlet obstruction. $J$ perinatal.1996;16(4):285-7.

5. Bauer SB, Retik AB. The non-obstructive ectopic Ureterocoele. J Urol. 1978;119(6):804-7.

6. Blyth B, Passerini Glazel G, Camuffo C, et al. Endoscopic incision of ureterocoeles Intravesical versus ectopic. J Urol. 1993;149(3):556-9.

7. Chertin B, Mohanan N, Farkas A, et al. Endoscopic treatment of vesico ureteral reflux associated with ureterocele. JUrol. 2007;178(4pt2):1594-7.

8. Husmans DA, Ewalt DH, Glenski WJ, et al. Ureterocele associated with ureteral duplication and a non-functioning upper pole segment. Management by partial nephroureterectomy alone. J Urol. 1995;154(2pt2):733-6.

9. Lewis JM, Cheng EY, Campbell JB, et al. Complete excision or marsuphlization of ureteroceles: does choise of surgical approach affect outcome. J Urol. 2008:180(4suppl);1819-22.

10. Storm DW, Modi A, Janathi VR. Laparoscopic ipsilateral ureteroureterostomy in the management of ureteral ectopia in infants and children. J Pediatr Urol. 2011;7(5):529-33. 